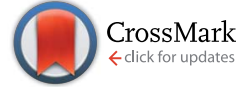

Cite this: RSC Adv., 2017, 7, 15613

\title{
Hyaluronic acid-based carbon dots for efficient gene delivery and cell imaging $\dagger$
}

\author{
Hai-Jiao Wang, Ji Zhang, * Yan-Hong Liu, Tian-Ying Luo, Xi He and Xiao-Qi Yu*
}

A strategy that uses hyaluronic acid ( $\mathrm{HA}$ ) as a carbon source and polyethylenimine (PEI) as a passivant to construct carbon dots ( $\mathrm{HA}-\mathrm{Cds}$ ) was proposed. The synthetic method is simple and green and no additive was required. These carbon dots could emit strong blue fluorescence under UV light. FT-IR and ${ }^{1} \mathrm{H}$ NMR spectra confirmed that part of characteristic residues of HA and PEI remained in the HA-Cds structure. These materials had much lower cytotoxicity than PEI and high serum tolerance. Up to 50 times higher transfection efficiency than that of PEI was obtained in the presence of $10 \%$ serum. BSA protein adsorption, flow cytometry, and confocal microscopy assays also supported their good performance with serum. Furthermore, as multifunctional materials, HA-Cds had good intracellular imaging ability and displayed tunable fluorescence emission under varying excitation wavelengths. An HA competition assay showed that they may have target cell imaging ability in CD44 overexpressed cells. These materials with fluorescence activity also facilitated co-localization experiments by CLSM, which revealed that the DNA cargo could be effectively released into the cytosol, leading to effective gene transfection. These properties make the carbon dots promising candidates for in vivo diagnosis and gene therapy.

Received 3rd February 2017

Accepted 27th February 2017

DOI: 10.1039/c7ra01417a

rsc.li/rsc-advances dots (Cds) have drawn tremendous attention in the field of nanotechnology. ${ }^{\mathbf{8 9}}$ One-step hydrothermal or microwave (MW)assisted methods were widely used to construct Cds. ${ }^{10-12}$ Some inexpensive and biocompatible small molecules such as citrate, ${ }^{13}$ ascorbic acid, ${ }^{14}$ glucose,${ }^{15}$ and ethanol ${ }^{16}$ were often used as carbon resources. On the other hand, effective surface passivation is another essential step to produce Cds with high fluorescence intensity. ${ }^{8}$ Using polyamine compounds as passivation agents can not only enhance their fluorescence intensity but also allow straightforward installation of cationic charge on the surface of the nanoparticles, offering them DNA binding capacity. Liu and coworkers first used polyethylenimine (PEI)-functionalized Cds, which were prepared with PEI as a surface passivation agent through one-step MW-assisted pyrolysis of glycerol, as gene vectors. ${ }^{17}$ Wang et al. passivated Cds by using alkyl-PEI $2 \mathrm{kDa}$ for the safe and highly efficient delivery of siRNA and DNA. ${ }^{18}$ More recently, Pierrat and coworkers employed citric acid and bPEI $25 \mathrm{kDa}$ under MW irradiation to construct Cds as efficient gene nanocarriers. ${ }^{19}$ However, the designed Cds in these limited reports usually showed lower TE compared to PEI $25 \mathrm{kDa}$, and their preparation methods were not mild and convenient enough as they required additives (acid/salt) or harsh conditions (e.g. laser ablation).

Although branched PEI $25 \mathrm{kDa}$ has been used as a "golden standard" for non-viral gene vectors due to its high TE and universality for many cell lines, its high toxicity and low serum compatibility largely limit its use in vivo. ${ }^{20}$ The introduction of zwitterions or negatively charged groups into PEI is regarded as an effective method to overcome the above-mentioned
Key Laboratory of Green Chemistry and Technology (Ministry of Education), College of Chemistry, Sichuan University, Chengdu 610064, PR China.E-mail: jzhang@scu.edu. cn; xqyu@scu.edu.cn; Fax: +86-28-85415886

$\dagger$ Electronic supplementary information (ESI) available: Supplemental figures and compounds characterization. See DOI: 10.1039/c7ra01417a 
shortcomings. ${ }^{21-24}$ For example, polyethylene glycol (PEG) has been commonly used to improve the biocompatibility of cationic materials. ${ }^{25-27}$ Hyaluronic acid (HA) is another biocompatible species used in the formation of nano-vectors. The negative charges on HA may afford a similar "stealth effect" to that observed with PEG. ${ }^{28,29}$ Besides, it is also known that HA has a strong affinity to bind cell-specific surface markers such as cluster determinant 44 (CD44) receptors, which are overexpressed on various tumor cells. ${ }^{30,31}$ To the best of our knowledge, the use of two polymers with no additives (acid, base and/or oxidant) to directly construct Cds by a MW-assisted method has not yet been reported. Herein, we prepared a class of Cds by using HA as a carbon source and PEI as a surface passivation agent via simple MW-assisted pyrolysis. We hope that the resulting nanomaterials will combine the advantages of Cds, PEI, and HA and will act as multifunctional biocompatible materials for simultaneous gene delivery and cell imaging.

\section{Results and discussion}

\section{Preparation and characterization of HA-Cds}

MW-assisted Cd preparation always uses small molecules as carbon sources or additives. In this work, we prepared six HAbased Cds (HA-Cds) by direct MW-assisted pyrolysis of PEI 25 $\mathrm{kDa}$ and HA with no additives (Scheme 1). Under MW irradiation, HA was dehydrated and then PEI was passivated to form the Cds. As HA and PEI are both polymers, their residues would be retained on the HA-Cd surface under the relatively mild preparation conditions. The cationic amino groups on the PEI residues can help the HA-Cds to bind and condense negatively charged DNA, while the HA residues might improve their biocompatibility. These Cds were named as HA-CPx , in which $\mathrm{CP}$ refers to the Cd-based polymer and $x$ indicates the total MW irradiation time ( $\mathrm{min}$ ) for the preparation. Subsequently, the optical properties of these Cds were studied. As shown in Fig. 1A, all of the prepared HA-Cds (for the other three see Fig. S1 $\dagger$ ) emitted strong blue luminescence under UV light (365 $\mathrm{nm})$. At this excitation wavelength, the maximum emission wavelength $\left(\lambda_{\mathrm{em}}\right)$ of HA-CP10 was found to be $470 \mathrm{~nm}$ and the maximum excitation wavelength $\left(\lambda_{\text {ex }}\right)$ was measured as $345 \mathrm{~nm}$ (Fig. 1B). The full width at half maximum (FWHM) under excitation at $365 \mathrm{~nm}$ was about $79 \mathrm{~nm}$, which was smaller than the values reported in the literature. ${ }^{17,32} \mathrm{We}$ also studied the optical properties of five other Cds, and similar results were obtained (Fig. S2†). Transmission electron microscopy (TEM) was performed to study the morphology of HA-CP10, and the anhydrous state particle diameter was measured as $32.5 \pm$ $0.5 \mathrm{~nm}$ (Fig. 1C and D). Atomic force microscopy (AFM) images showed that the height of the HA-CP10 particles was 1 to $3.5 \mathrm{~nm}$ (Fig. S3†). The X-ray diffraction (XRD) pattern (Fig. 1E) displays a broad diffraction peak at $2 \theta=24.4^{\circ}$, suggesting an amorphous nature. In addition, dynamic light scattering (DLS) was also applied to characterize the hydrodynamic sizes of these HA-Cds (Table S1 $\dagger$ ). When the microwave irradiation time was

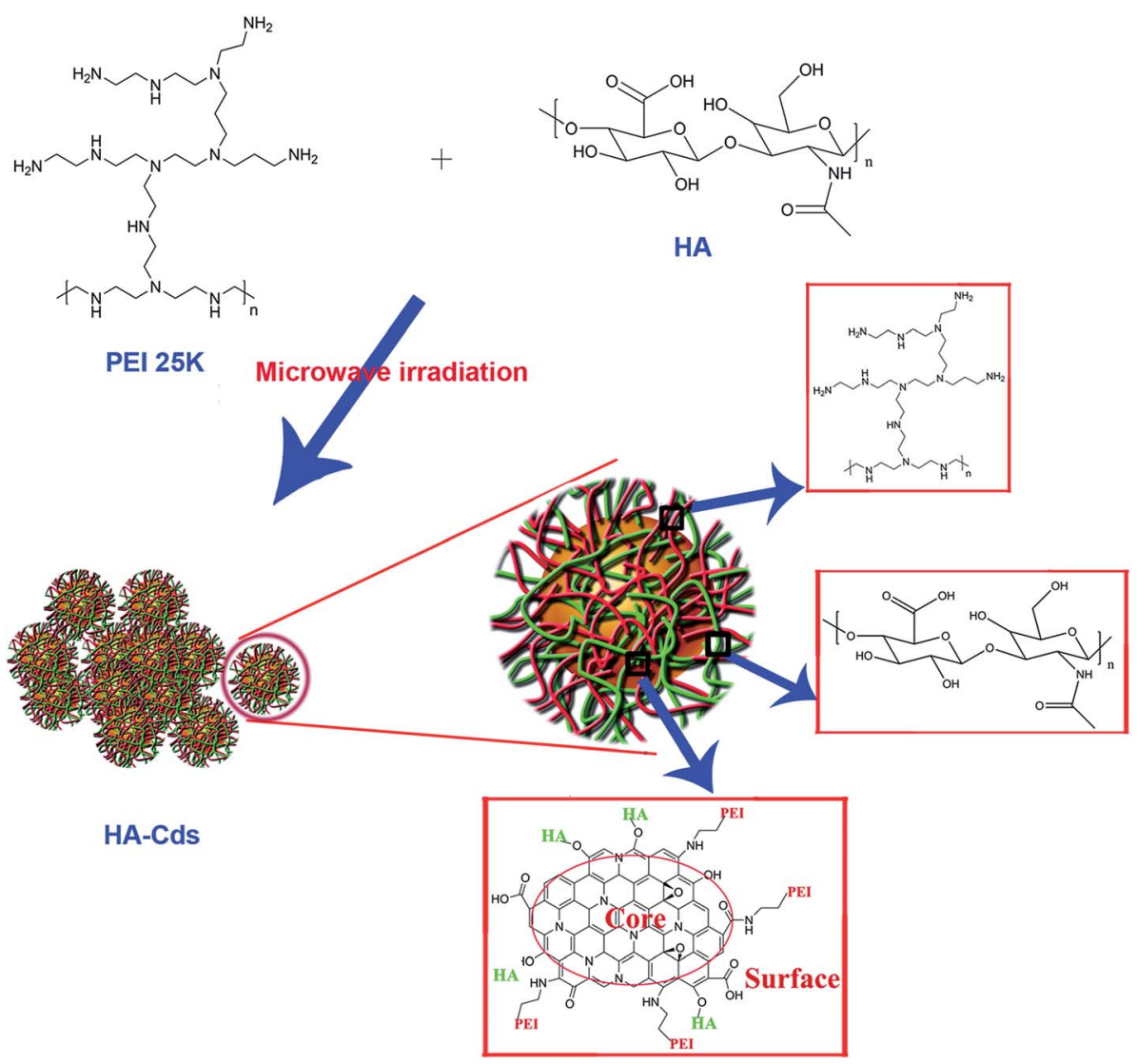

Scheme 1 Schematic of the synthesis and structure of HA-Cds. 

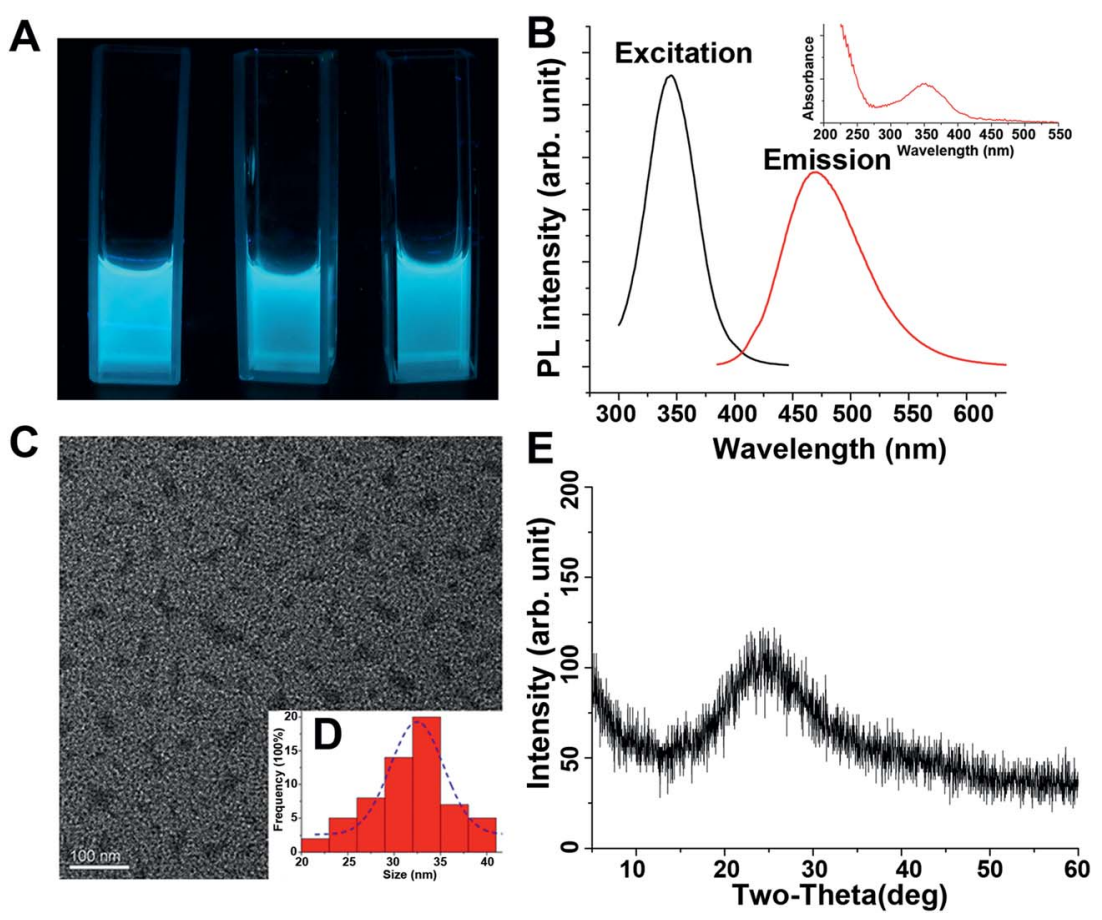

Fig. 1 (A) Aqueous HA-Cd solutions under UV light illumination (365 nm, from left to right: HA-CP5, HA-CP10, and HA-CP20). (B) Photoluminescence and UV spectra (inset) of aqueous HA-CP10 solution. (C) TEM image of HA-CP10. (D) Particle size distribution curve from TEM. (E) XRD patterns for HA-CP10.

increased, their hydrodynamic sizes gradually decreased. This may be due to the increased consumption of PEI and HA residues as the irradiation time is increased.

FT-IR was employed to identify the organic functional groups on the HA-Cds (Fig. S4†). The new strong peak at 1630 $\mathrm{cm}^{-1}$ reflects the presence of amide carbonyls, indicating successful conjugation between amines of PEI and carboxyls of HA. On the other hand, after microwave irradiation, some characteristic absorption peaks of raw PEI and HA remained in the spectra of the Cds. For example, the absorbance peaks of $\mathrm{HA}$ at $1388 \mathrm{~cm}^{-1}$ and $1049 \mathrm{~cm}^{-1}$ were attributed to carboxylate symmetric stretching and $\mathrm{C}-\mathrm{O}$ stretching, respectively, and a broad band centered at $3432 \mathrm{~cm}^{-1}$ might suggest the existence of $-\mathrm{OH}$ and $-\mathrm{NH}$. Their chemical structures were also characterized by ${ }^{1} \mathrm{H}$ NMR (Fig. S5 $\dagger$ ). Multiplets with a chemical shift $(\delta)$ of $2.4-2.8 \mathrm{ppm}$ were attributed to protons on the $-\mathrm{CH}_{2} \mathrm{~N}-$ of PEI, which was successfully passivated in the HA-Cds. As with the IR analysis, characteristic NMR peaks of HA could still be found in the spectra of HA-Cds, further indicating that HA did not completely transform to the carbon core and some of its residues remained even after extended MW irradiation. For the HA-Cds, after various MW treatment times, no obvious differences were found in either the IR or NMR spectra. We therefore suppose that the six Cds might have similar structures and compositions. This was further proved by elemental analysis, which also gave similar $\mathrm{C}, \mathrm{N}$, and $\mathrm{H}$ contents for all the HA-Cds (Table S2 $†$ ).

One important characteristic of PEI is its buffering ability over a wide range of $\mathrm{pH}$ values. This buffering property is known as the "proton sponge effect" and might enable PEI to escape more efficiently from the endosome. ${ }^{1}$ Therefore, the buffering capacities of these PEI-passivated HA-Cds, expressed as the percentage of amine groups that could be protonated within the endosome $\mathrm{pH}$ range of 7.4-5.1, were determined from acidbase titration. As shown in Table 1, although part of the PEI structure was damaged during the formation of these carbon dots by MW irradiation, these HA-Cds showed only slightly lower buffering capacity than PEI. In other words, most of the buffering capacity of PEI remained after the preparation of HA-Cds.

The fluorescence emissions of the Cds may depend on the $\lambda_{\text {ex }}{ }^{8}$ The photoluminescence spectra recorded for HA-CP10 with $\lambda_{\text {ex }}$ ranged from 345 to $405 \mathrm{~nm}$ (Fig. S6A $\dagger$ ). With an increase in $\lambda_{\mathrm{ex}}$, the fluorescence intensity decreased remarkably. Meanwhile, the normalized photoluminescence spectra

Table 1 Buffering capacity of HA-Cds

\begin{tabular}{|c|c|c|c|c|c|c|c|}
\hline & PEI & HA-CP5 & HA-CP10 & HA-СР20 & HA-CP30 & HA-СР40 & HA-CP50 \\
\hline Buffering capacity & $20.1 \%$ & $16.8 \%$ & $14.4 \%$ & $15.0 \%$ & $14.5 \%$ & $14.7 \%$ & $16.5 \%$ \\
\hline
\end{tabular}


revealed a small emission peak shift in the $\lambda_{\text {ex }}$ range $345-$ $395 \mathrm{~nm}\left(\Delta \lambda_{\mathrm{em}}=10 \mathrm{~nm}\right.$, Fig. S6B $\left.\dagger\right)$, which was in agreement with the literature. ${ }^{19}$ Quinine sulfate in $0.10 \quad \mathrm{M} \mathrm{H}_{2} \mathrm{SO}_{4}$ (quantum yield 54\%) was selected as a standard sample to calculate the quantum yields of the HA-Cds, and the Cds prepared with $10 \mathrm{~min}$ MW treatment (HA-CP10) gave the highest quantum yield (Table $\mathrm{S} 3 \dagger$ ). We speculate that the carbon core was not properly formed before $10 \mathrm{~min}$ but, on the other hand, when the MW irradiation time was increased, more HA would dehydrate to form a larger carbon core while more PEI was passivated on it, finally leading to a decrease in the photoluminescence performance. It was also reported that the MW pyrolysis time would significantly affect the photoluminescence performance. ${ }^{17}$

\section{Interactions between the HA-Cds and plasmid DNA}

The ability of cationic gene vectors to condense DNA into nanosized particles is a crucial factor for efficient cell transfection. A gel retardation assay was used to confirm the interaction between the HA-Cds and plasmid DNA at various weight ratios, and the results are shown in Fig. 2A. As the weight ratio increased, the intensity of the DNA migration bands in the agarose gel decreased. All the HACds could completely inhibit the electrophoretic mobility of plasmid DNA at a Cd/DNA weight ratio of $1: 1$, suggesting that all the HA-Cds could effectively condense plasmid DNA though electrostatic interactions at a low dose. In addition, since a longer MW pyrolysis time did not reduce the DNA binding ability, it might be supposed that a considerable portion of the amino groups would remain on the surface of the Cds during the MW process. Furthermore, an ethidium bromide (EB) intercalation assay was also used to investigate the DNA affinity of these Cds. The fluorescence of EB can be greatly enhanced by its intercalation into double-stranded DNA, while the addition of gene vectors can expel EB from the intercalation site of the DNA, resulting in fluorescence quenching. ${ }^{33}$ As shown in Fig. 2B, both PEI and the HA-Cds could almost completely quench the fluorescence of the EB/DNA complex at low weight ratios (0.5 for PEI and 1.0 for HACds), further indicating their good DNA binding ability. The CE50 values, which represent the weight ratios required to quench $50 \%$ of the EB fluorescence intensity, were 0.19 for PEI and 0.45-0.52 for the HA-Cds. The higher values for the HA-Cds might be attributed to their lower $\mathrm{N}$ content (Table S1 $\dagger$ ) and the fact that some of the $\mathrm{N}$ atoms participated in the formation of the core and could not be protonated.

Appropriate sizes and zeta potentials are also of great importance for the gene carriers, as these can even determine the endocytosis pathway of the nanoparticles. ${ }^{34}$ DLS was applied to characterize these properties of the HA-Cd/DNA complexes at different weight ratios $(\mathrm{w} / \mathrm{w}=0.5,2,6,8,10,12$, Fig. 3). The complexes showed particle sizes in the range $240-360 \mathrm{~nm}$ at the tested weight ratios. Other researchers have found that complexes with sizes between 50 and several hundred nanometers were suitable for cell uptake. ${ }^{35-37}$ The zeta potentials of the six complexes were also evaluated and found to increase from $-5 \mathrm{mV}$ to $+44 \mathrm{mV}$ along with an increase in the weight ratios. In general, nanoparticles with a higher positive charge exhibited a stronger affinity for the negatively charged cell membrane, resulting in higher cellular uptake. ${ }^{38,39}$ Our previous studies found that better gene transfection efficiency could be obtained when the surface charges of the complexes were higher than $+20 \mathrm{mV} \cdot .^{40-42}$ In this case, we also found that $\mathrm{w} / \mathrm{w} \geq 6$ (zeta potential > $+20 \mathrm{mV}$ ) is required for efficient transfection.

\section{Cytotoxicity}

High cytotoxicity is a major barrier that significantly limits the use of non-viral gene vectors for gene therapy in clinical applications. Cds have been reported with low toxicity and excellent biocompatibility. ${ }^{43}$ Meanwhile, the strategy of introducing tissue-friendly HA to Cds might further enhance their biocompatibility. The cell viability after $24 \mathrm{~h}$ incubation with HA-Cd/DNA complexes at various weight ratios was evaluated in HeLa cells. As we hoped, these HA-Cd/DNA complexes all have much lower cytotoxicity than PEI (Fig. 4). As the weight ratio increased, the cell viability reduced gradually but only slightly. Even at a high weight ratio of 14 , the percentage of surviving cells was still more than $80 \%$, while this value was only $20 \%$ for PEI under the same conditions.

\section{In vitro gene transfection}

To evaluate the transfection efficiency (TE) of these HA-Cds as non-viral gene delivery vectors, a luciferase transfection assay of
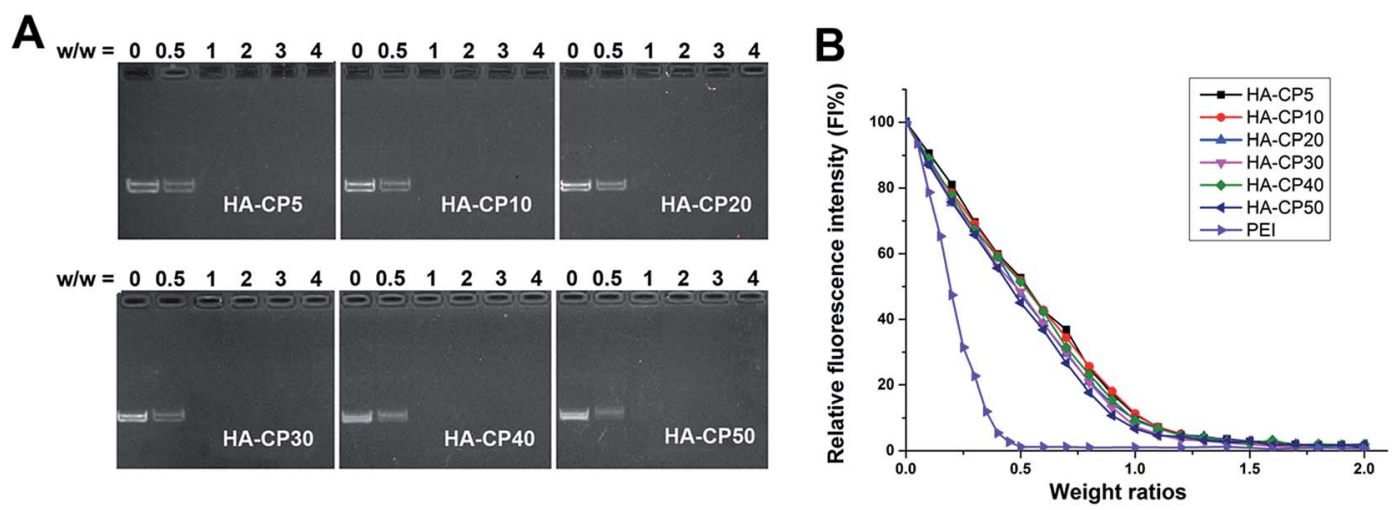

Fig. 2 (A) Agarose gel electrophoresis of HA-Cd/DNA complexes at different weight ratios. In each image, the first lane is the DNA control. (B) Fluorescence quenching assay of EB/DNA by the addition of HA-Cds, $25 \mathrm{kDa}$ PEI was used as a control. 

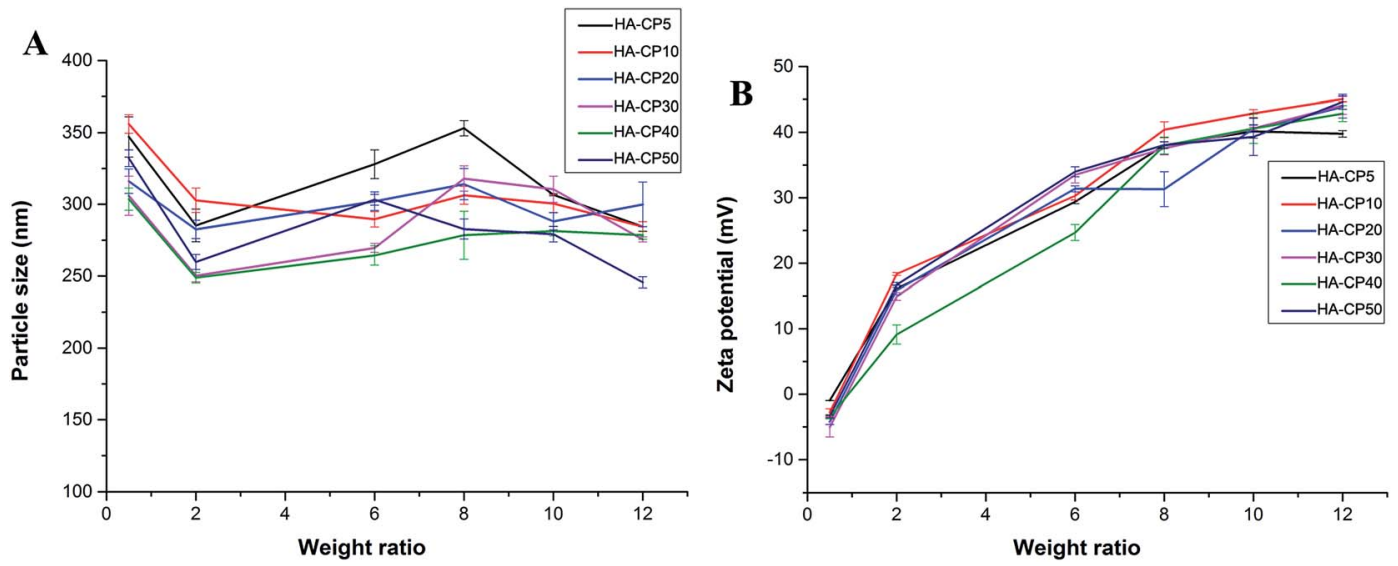

Fig. 3 Average particle size (A) and zeta-potential (B) of HA-Cd/DNA complexes at different weight ratios (data represent mean $\pm \mathrm{SD}, n=3$ ).

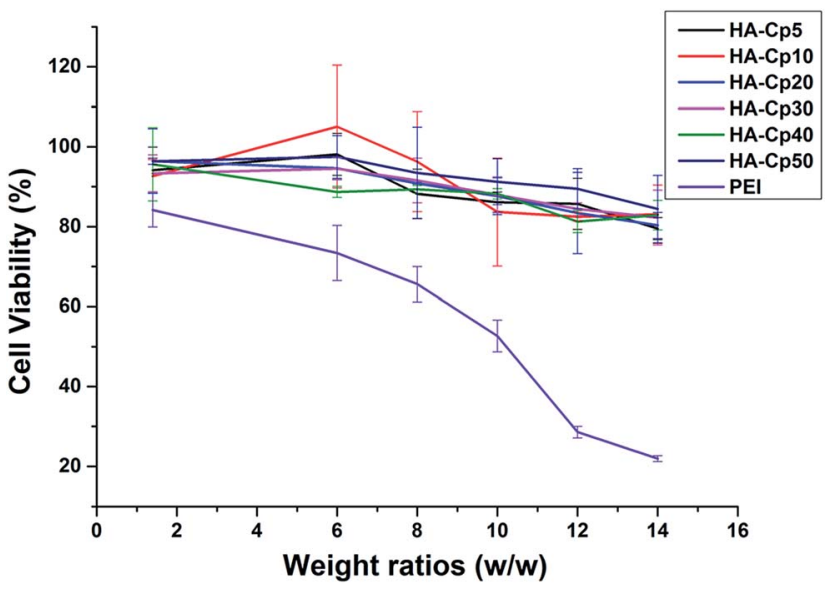

Fig. 4 Cytotoxicity of HA-Cd/DNA complexes at different weight ratios ( $\mathrm{w} / \mathrm{w}=1.4,6,8,10,12,14)$ toward HeLa cells; $25 \mathrm{kDa} \mathrm{PEI}$ was used as a control. Data represent mean \pm SD $(n=3)$.

HA-Cd/DNA complexes at various $\mathrm{w} / \mathrm{w}$ ratios was carried out in HeLa cells (Fig. 5) in comparison with $25 \mathrm{kDa}$ PEI, which was used at its optimal w/w ratio of 1.4 (N/P ratio of 10$)$. Before the luciferase transfection, a non-quantitative enhanced green fluorescent protein (eGFP) expression assay was performed to preliminarily optimize the HA-Cd/DNA weight ratio, and it was found that $\mathrm{a} w / \mathrm{w} \geq 6$ is required for efficient transfection (Fig. S7 $\dagger$ ). The quantitative data also revealed that an increase in the weight ratio led to a significantly increased TE (Fig. 5A). At the optimized weight ratio, all the HA-Cds exhibited 3-4 times higher TE than PEI. Generally, during the formation of Cds involving PEI, the amino groups on PEI were partly consumed to form amide bonds or Cd cores, leading to reduced TE compared to PEI. ${ }^{17}$ However, our results showed that the PEI-passivated HA-Cds did not reduce but largely enhanced the TEs. We speculated that the low cytotoxicity of the HA-Cds and the formation of core-shell structures might contribute to the enhanced transfection level. ${ }^{17}$ With respect to the MW time span, it was found that $10 \mathrm{~min}$ of MW irradiation was most suitable for the preparation of HA-Cds with high TE. Extending the MW treatment might lead to greater consumption of the amino groups on PEI, which are essential for DNA binding and transfection; thus, a decreased TE might be obtained.

It is believed that the toxicity of polycations, the inadequate release of DNA molecules, and the low availability of the vectors
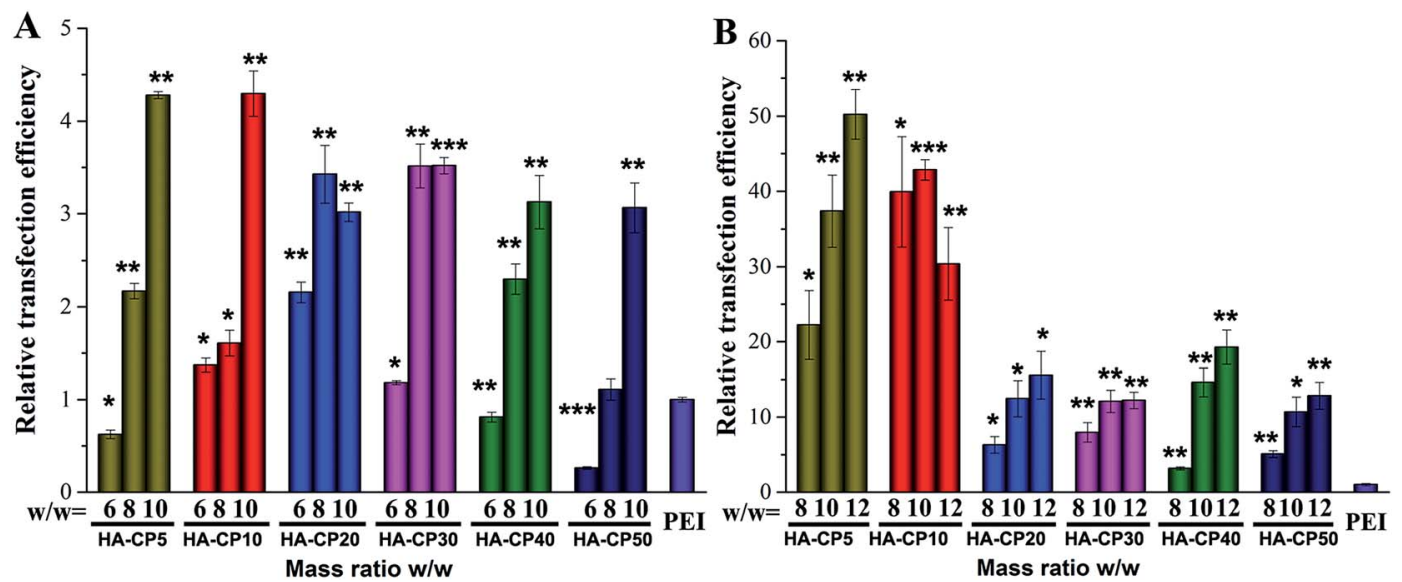

Fig. 5 Luciferase gene expression transfected with HA-Cd/DNA complexes at different weight ratios in comparison with $25 \mathrm{kDa} P \mathrm{PEl}(\mathrm{N} / \mathrm{P}=10)$ in HeLa cells (unless otherwise noted). (A) Without serum; (B) with serum (10\%). Data represent mean $\pm \mathrm{SD}(n=3, * P<0.05 ; * * P<0.01 ; * * *<<0.001$ vs. PEI). 
caused by aggregation with protein molecules in complex media or a lack of DNA protection are key reasons for a low TE. ${ }^{\mathbf{4}}$ The serum components, especially negatively charged proteins, always exhibit non-specific interactions with cationic vector/ DNA complexes, leading to a significantly decreased TE. ${ }^{45}$ To solve this problem, we introduced electronegative HA to the materials in the hope that such a component, especially its reserved residues, may reduce the cytotoxicity and avoid the dramatic reduction in TE in the physiological environment

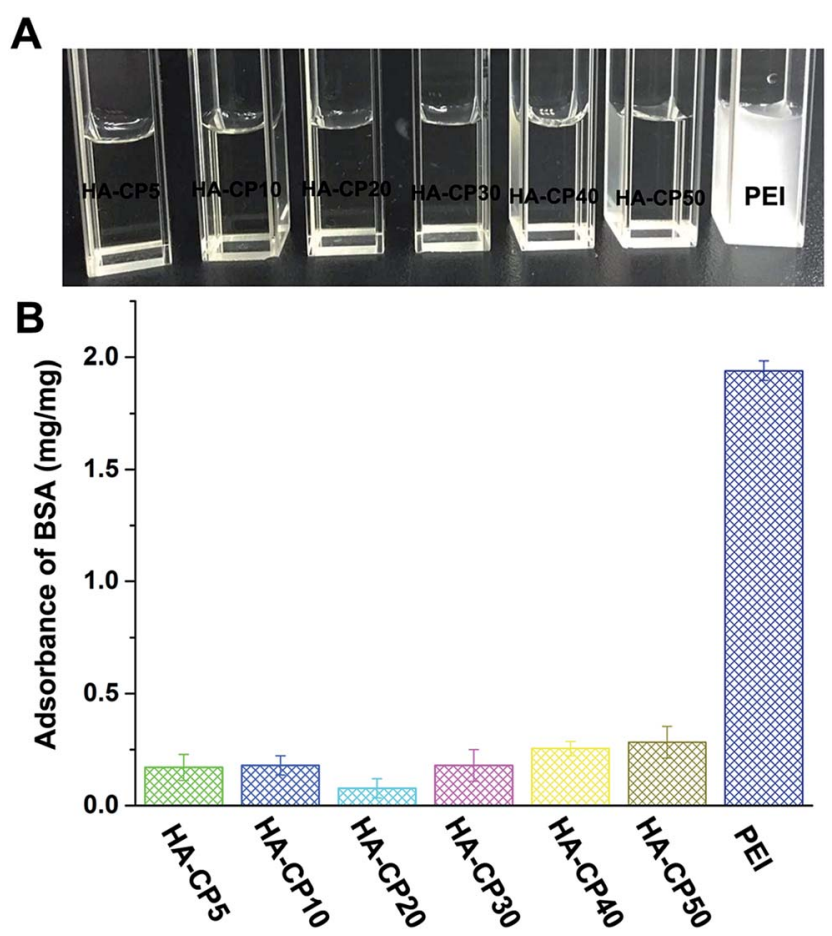

Fig. 6 Protein adsorption of the HA-Cds and PEI: (A) intuitive picture; (B) quantitative results. Data represent mean $\pm \mathrm{SD}(n=3)$. caused by strong protein adsorption by the cationic gene vector. To our delight, HA-Cds showed significantly higher serum tolerance than PEI. In the presence of serum, a TE of up to 50 times higher than that of PEI was obtained (Fig. 5B). Thus, we believe that the HA residue may exhibit a "stealth effect" and effectively resist non-specific protein adsorption. As with the transfection without serum, HA-Cds prepared via a shorter MW irradiation time have better TE. The transfection in HEK293 cells also confirmed the good serum tolerance of the HA-Cds (Fig. S8†).

To visually compare the gene transfer ability of the studied Cds, we also transfected pEGFP-Nl reporter genes into HeLa cells using an inverted fluorescence microscope for observation. Based on the results from luciferase and cytotoxicity assays, a HA-Cd/DNA weight ratio of 10 was chosen for transfection. The images in Fig. $\mathrm{S} 9 \dagger$ give similar results to the luciferase assay. The transfection mediated by HA-Cds led to much stronger green fluorescence than that using PEI, especially in the presence of serum. Besides, unlike with PEI, the density of transfected cells was seldom affected by the serum, further indicating the good biocompatibility of our materials.

Bovine serum albumin (BSA) was selected as a model protein to simulate the $10 \%$ serum condition and to determine the interactions between the vectors and serum components (Fig. 6). After PEI was added, the BSA solution became turbid immediately, indicating fast electrostatic adsorption, which led to aggregation and precipitation. Meanwhile, on the contrary, the HA-Cds caused little aggregation, and the BSA solutions remained transparent after incubation with these Cds. The amount of BSA adsorbed per mg of these cationic materials was also calculated, and the quantitative results exhibited a large difference in the adsorption amount of BSA. This may indicate the good serum tolerance of HA-Cds. In addition, we also studied the stability of HA-Cds (HA-CP10 was chosen as the model) toward $10 \%$ fetal bovine serum (FBS, v/v) and different concentrations of bull serum albumin (BSA, $0.1 \mathrm{mg} \mathrm{mL}^{-1}$ and
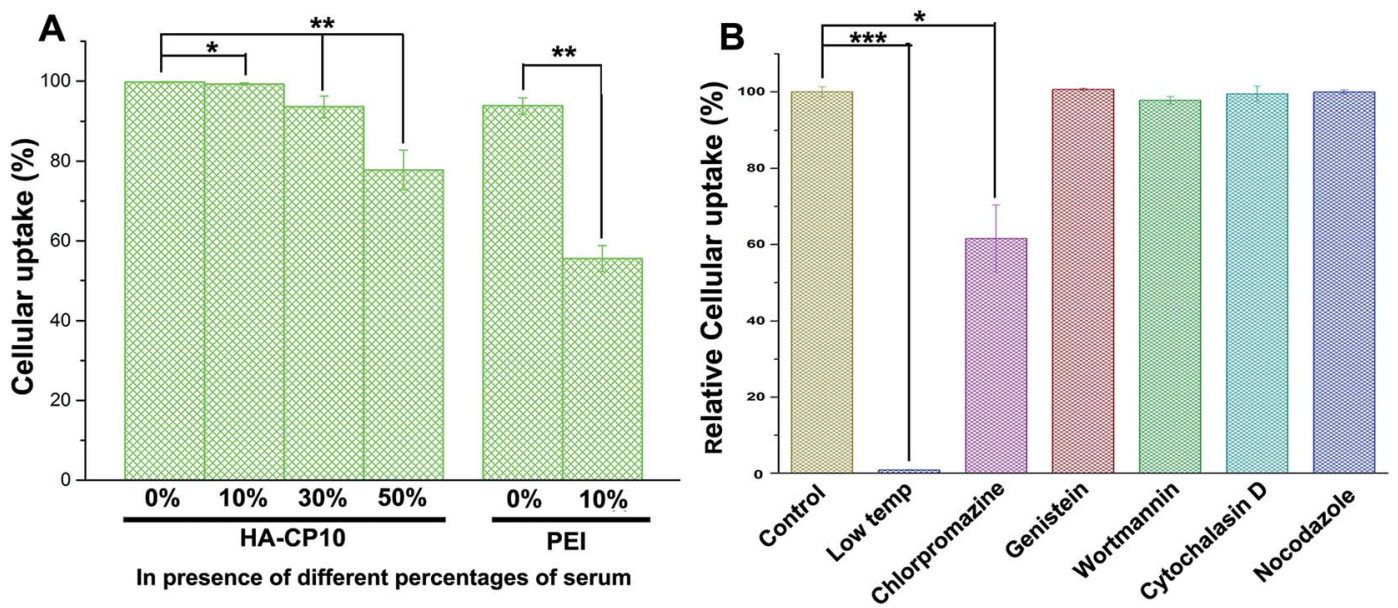

Fig. 7 (A) Cellular uptake of HA-CP10/DNA complexes in HeLa cells with different concentrations of serum quantified by flow cytometry analysis; $25 \mathrm{kDa}$ PEI was used as a control. (B) Relative cellular uptake of HA-CP10/DNA complexes at a weight ratio of 10 in HeLa cells at $4{ }^{\circ} \mathrm{C}$ or in the presence of various endocytic inhibitors quantified by flow cytometry analysis. Data represent mean $\pm \operatorname{SD}(n=3, * P<0.05 ; * * P<0.01 ; * * * P$ $<0.001)$ 
$0.2 \mathrm{mg} \mathrm{mL}^{-1}$ ) solutions (Table $\mathrm{S} 4 \dagger$ ). Although the hydrodynamic particle size of HA-CP10 increased to $113.8 \mathrm{~nm}$ toward 10\% FBS, the size seldom changed over 3 days, suggesting good stability under protein-rich conditions.

As one of the main barriers in the gene delivery process, the internalization of the nucleic acid complexes largely influences the TE. Flow cytometry was performed to analyze the cellular uptake of DNA. Based on the results of the quantum yields of the HA-Cds, the luciferase assays, and the cytotoxicity, HA-CP10 was chosen as the model. After incubation of the HA-CP10/DNA complexes (at a weight ratio of 10) with HeLa cells for $4 \mathrm{~h}$, the percentage of cells that were positive for Cy5-labeled pDNA was calculated (Fig. 7A). In the absence of serum, HA-CP10 exhibited excellent cellular uptake, and the percentage of positive cells was $\sim 99.7 \%$. At a serum content of $10 \%$, no obvious decrease in the cellular uptake percentage was found. Although a further increase in the serum concentration led to a gradually reduced uptake, a good percentage of positive cells (77.8\%) could also be obtained with $50 \%$ serum. On the other hand, for PEI, the percentage of positive cells decreased dramatically to $55.5 \%$ with $10 \%$ serum. The results also demonstrate the good stability of HA-Cds in extracellular circumstances, and the much better resistance toward serum proteins makes it easier for the HA-Cd complexes to reach the cells. Furthermore, the uptake pathway of HA-Cd/DNA complexes was also studied. Endocytosis has been demonstrated to adopt a variety of forms, such as macropinocytosis, clathrin-mediated endocytosis, and caveolaemediated endocytosis. ${ }^{46,47}$ After incubation at $4{ }^{\circ} \mathrm{C}$, the cellular

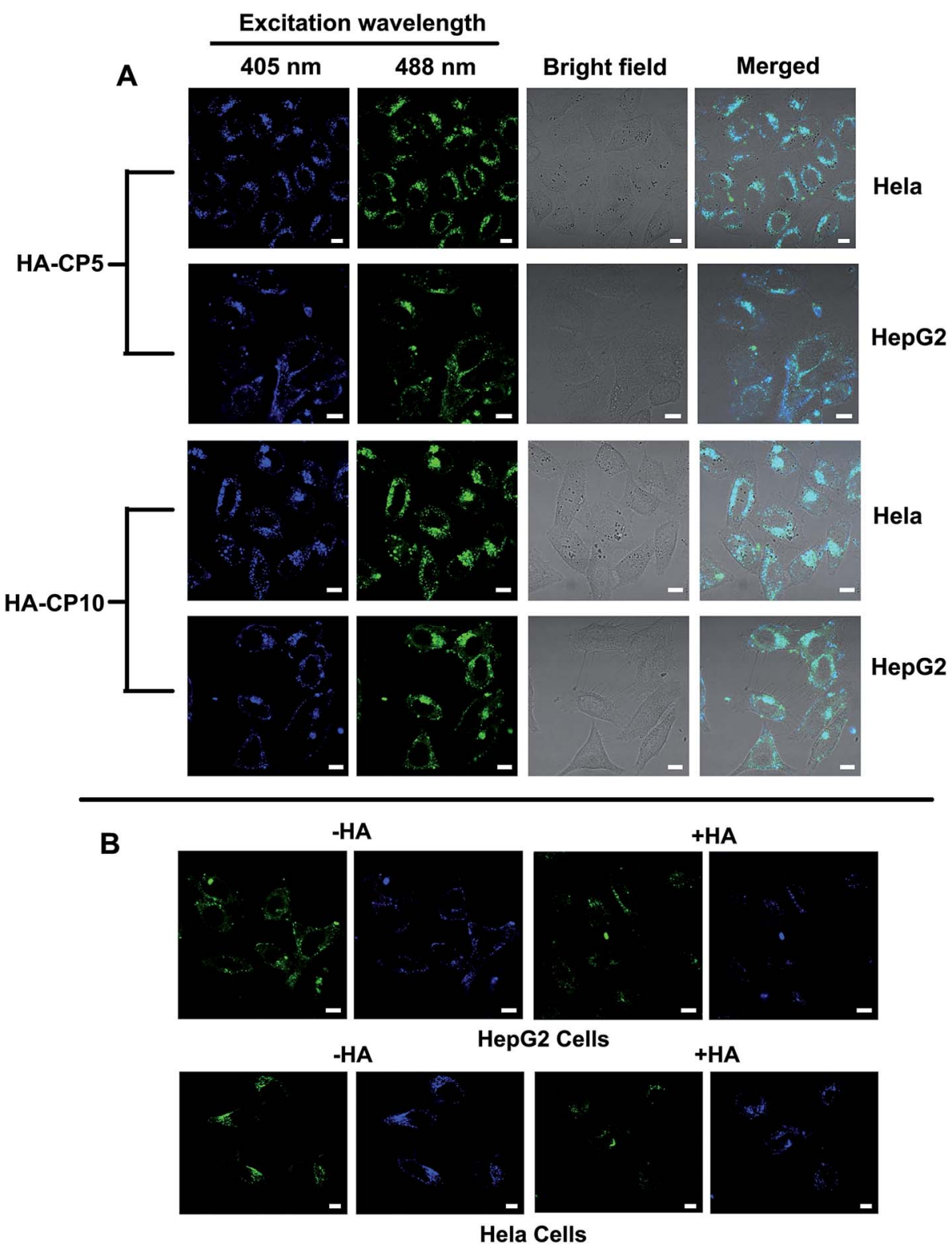

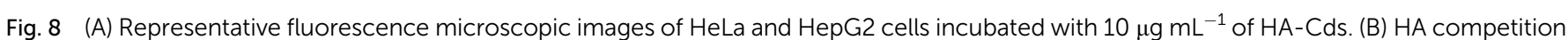
assay of HA-CP10 $\left(10 \mu \mathrm{g} \mathrm{mL}^{-1}\right)$ in HeLa cells and HepG2 cells $(-\mathrm{HA}$ : without HA. +HA: addition of 100 -fold excess of HA to the cells for $2 \mathrm{~h}$ before the treatment with $\mathrm{HA}-\mathrm{Cds}$ ). Scale bar $=10 \mu \mathrm{m}$. 
uptake almost ceased (Fig. 7B), indicating that the complexes enter the cells mainly via energy-dependent pathways. The uptake mechanism of such a complex was subsequently studied by using different chemical endocytosis inhibitors. Wortmannin is a phosphatidyl inositol-3-phosphate inhibitor, ${ }^{48}$ while cytochalasin $\mathrm{D}$ can inhibit actin polymerization and membrane ruffling; ${ }^{49}$ both of these can inhibit the macropinocytosis pathway. Chlorpromazine, genistein, and nocodazole may inhibit the pathways of clathrin-mediated, caveolae-mediated, and microtubule-mediated endocytosis, respectively. The results shown in Fig. 7B reveal that only chlorpromazine may lead to an obvious decrease in cellular uptake, indicating that clathrinmediated endocytosis might be the major cellular uptake pathway for such a complex. Previous reports have suggested that such an endocytosis pathway might be the most efficient uptake process as it could facilitate the orientation of DNA cargo to the perinuclear region and the subsequent nuclear import. ${ }^{50,51}$

Confocal laser scanning microscopy (CLSM) was utilized to visually examine the internalization of Cy5-labeled DNA (red) in HeLa cells (Fig. S10 $\dagger$ ). After $1 \mathrm{~h}$ incubation, the red signals could be easily found in the cells. It is worth mentioning that for the HA-CP10-mediated transfection, the guest DNA was mostly distributed in the cytosol, while for the PEI-mediated experiment, most of the Cy5-labeled DNA was distributed close to the cell membrane. This also indicates that transfection by HACP10 occurs at a higher rate. As a result, more DNA cargoes could be delivered by HA-CP10 than by PEI, especially for longer transfection times (4 h, Fig. S10 $\dagger$ ).

\section{Cell imaging studies}

As a type of newly emerged fluorescent nanomaterial, Cds have been widely used in bioimaging, chemical sensing, and biosensing. ${ }^{8}$ To evaluate the bioimaging ability of the HA-Cds, two selected materials (HA-CP5 and HA-CP10) were first incubated with HeLa and HepG2 cells and then observed by CLSM. As shown in Fig. 8A, bright fluorescence could be found in both cell lines owing to the strong fluorescence emitted from HA-Cds. Under different $\lambda_{\text {ex }}$, HA-Cds could stain cells with different colours (blue and green under $\lambda_{\mathrm{ex}}$ of 405 and $488 \mathrm{~nm}$, respectively). As elucidated from the optical spectra, after MW irradiation, some HA residues remained on the surface of the HA-Cds. Therefore, HA-Cds might have targeting imaging ability with respect to cells overexpressing CD44 (such as HeLa and HepG2 cells). ${ }^{52,53}$ An HA competition assay was carried out to evaluate the targeting imaging ability of these HA-Cds in HeLa and HepG2 cells. The results shown in Fig. 8B revealed that after preincubation of the cells with free HA, the fluorescence intensity of the HA-Cds decreased in both cell lines. Since the free HA may competitively bind to the receptors on the cell membrane, such a decrease may be reasonable, and it also demonstrated that these HA-Cds have target cell imaging ability.

The good fluorescence properties of these Cds could also be utilized to study the gene transfection process. ${ }^{54}$ The CLSM images of HA-CP10/Cy5-DNA complexes after different transfection times in HeLa cells are shown in Fig. 9. The green signal of HA-CP10 and the red signal of Cy5 overlapped significantly after $1 \mathrm{~h}$ transfection, and only the merged yellow signal could be observed. This indicates that almost all Cy5-DNA cargos were co-localized with HA-CP10 vectors. With an increase in the transfection time, stronger fluorescence signals were found and, more importantly, more and more red signals could be observed in the merged image, especially after $24 \mathrm{~h}$ transfection (Fig. 9c). Such results suggest that some of the HA-CP10/Cy5-

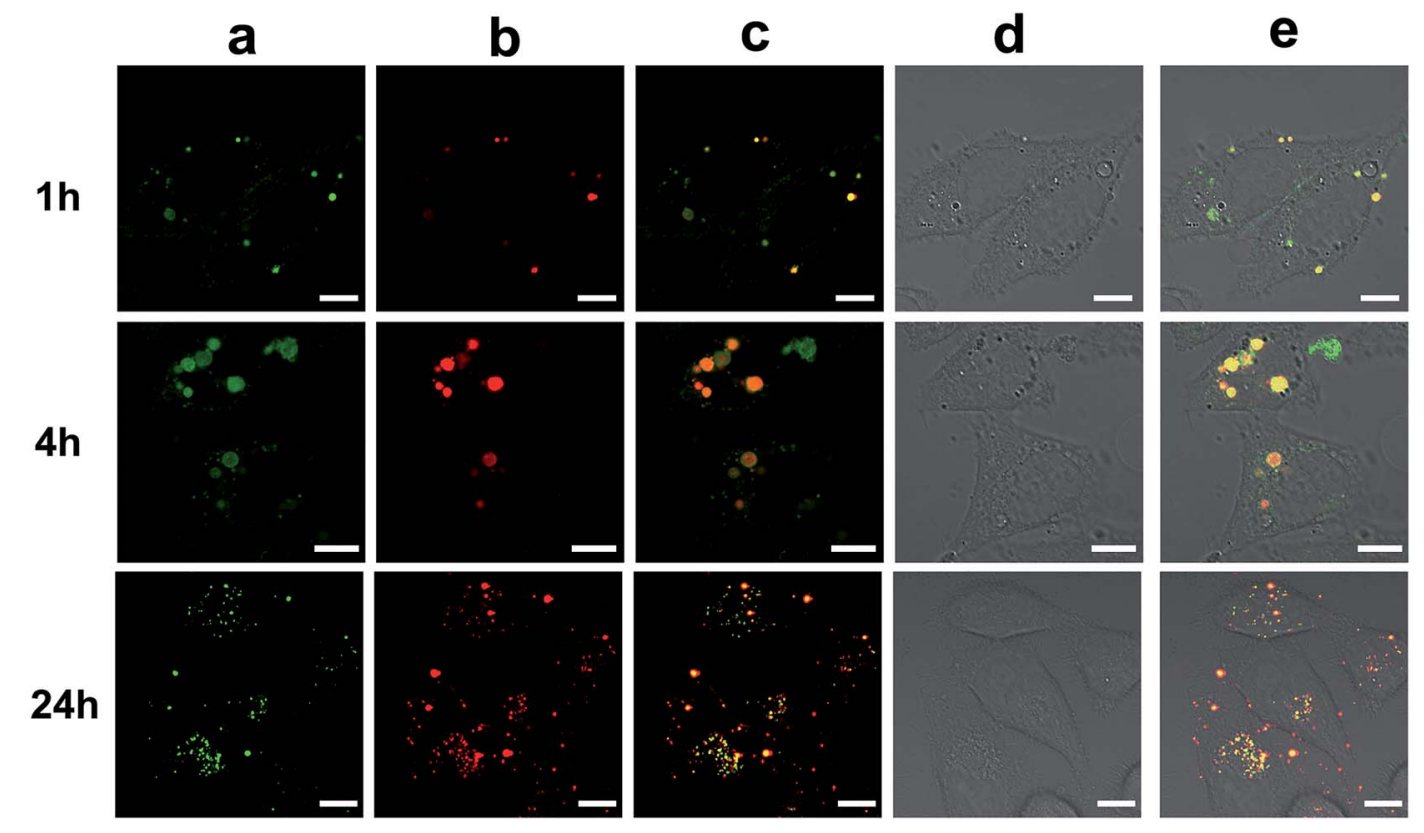

Fig. 9 Cellular imaging of HA-CP10/Cy5-DNA complexes in HeLa cells. Cells were incubated for various periods of time (1, 4, and $24 \mathrm{~h})$. (a) $\lambda_{\text {ex }}=$ $488 \mathrm{~nm}$ (HA-CP10); (b) $\lambda_{\mathrm{ex}}=635 \mathrm{~nm}$ (Cy5-DNA); (c) merged images of (a) and (b); (d) bright field; (e) merged images. Scale bar = $10 \mu \mathrm{m}$. 
DNA complexes have decomposed and free DNA has been released. It is well known that the dissociation of the vectors/ DNA complex is a necessary step for effective gene delivery. ${ }^{55}$ Consequently, HA-Cds may not only deliver DNA into the cells effectively, but may also act as efficient fluorescence signals, which help us to understand the transfection process and its mechanism.

\section{Conclusions}

In summary, a new type of carbon dots was obtained from HA and PEI via MW-assisted preparation with no additives. It was hoped that these materials would combine the good gene transfection efficiency of PEI with the targeting properties and biocompatibility of HA. Meanwhile, the fluorescence properties may also endow these Cd materials with cell imaging ability. Some characterization methods, including FT-IR and NMR, indicated that some characteristic residues of HA and PEI remained in the $\mathrm{Cd}$ structure. Subsequent experiments revealed that the elaborately designed Cds exhibited much lower cytotoxicity and higher TE than PEI in HeLa cells. Besides the low toxicity, these materials also show good serum tolerance, and a TE of up to 50 times higher than that of PEI was obtained in the presence of $10 \%$ serum. Several assays, including BSA adsorption, flow cytometry, and confocal microscopy, also proved their good transfection performance. Meanwhile, their particular fluorescence properties provide these Cds with cell imaging ability, allowing the DNA transportation process to be monitored. Under different $\lambda_{\text {ex }}$, HA-Cds could stain cells green or blue. An HA competition assay showed that these HA-Cds have target cell imaging ability in CD44 overexpressed cells. The materials with fluorescence activity also facilitated colocalization experiments by CLSM, which revealed that the DNA cargo could be effectively released into the cytosol, leading to effective gene transfection.

\section{Materials/methods}

\section{Materials and methods}

All chemicals and reagents were obtained commercially and were used as received. The ${ }^{1} \mathrm{H}$ NMR spectra were measured on a Bruker AM400 NMR spectrometer with $\mathrm{D}_{2} \mathrm{O}$ as solvent. Fourier transform infrared spectroscopy (FT-IR) was performed on an FTIR Nicolet 380 spectrometer. The composition of the HAbased Cds (HA-Cds) was determined by elemental analysis on an Elementar Vario EL III apparatus. TEM observations were performed on a Tecnai G2 F20 S-TWIN instrument. AFM measurements were carried out with a BRUKER INNOVA instrument. A luciferase assay kit was purchased from Promega (Madison, WI, USA). An endotoxin-free plasmid purification kit was purchased from TIANGEN (Beijing, China). Hyaluronic acid sodium salt $(6 \mathrm{kDa})$ was purchased from Bloomage Freda Biopharm Company Limited (Shandong, China). Branched polyethylenimine (PEI $25 \mathrm{kDa}$ ) with molecular weight $25 \mathrm{kDa}$ was purchased from Sigma-Aldrich (St Louis, MO, USA). The plasmids used in the study were pGL-3 (Promega, Madison, WI, USA) coding for luciferase DNA and pEGFP-N1 (Clontech, Palo
Alto, CA, USA) coding for EGFP DNA. The Dulbecco's modified Eagle's medium (DMEM), and fetal bovine serum were purchased from Invitrogen Corp. HEK293, HeLa, and HepG2 (liver hepatocellular carcinoma) cell lines were purchased from Shanghai Institute of Biochemistry and Cell Biology, Chinese Academy of Sciences.

Some experiments and methods, including cell culture, agarose gel retardation, ethidium bromide (EB) exclusion, quantum yield measurements, and dynamic light scattering (DLS) assays were carried out following previously reported procedures. ${ }^{19,36,42,56}$

\section{Preparation of HA-based Cds}

Briefly, hyaluronic acid sodium salt $(250 \mathrm{mg})$ and branched PEI $25 \mathrm{kDa}(250 \mathrm{mg}$ ) were dissolved in $50 \mathrm{~mL}$ (for HA-CP5) or $100 \mathrm{~mL}$ (For HA-CP10-HA-CP50) deionized water in a $250 \mathrm{~mL}$ beaker flask. The beaker flask was then placed at the center of the rotating plate of a domestic microwave oven $(700 \mathrm{~W})$ and heated for different time intervals. For HA-CP5, the solution was treated for $5 \mathrm{~min}$. For HA-CP10-HA-CP50, the solution was treated for $1,2,3,4$, and 5 intervals, respectively $(10 \mathrm{~min}$ for each interval, and before each interval, water was added to maintain the solution volume at $100 \mathrm{~mL}$ ). After heating, the yellow solution was dialyzed against $500 \mathrm{~mL}$ of $\mathrm{HCl}(\mathrm{pH}$ 1) for $24 \mathrm{~h}$ (MWCO $3500 \mathrm{Da})^{\mathbf{1 9}}$ and then against deionized water for another $48 \mathrm{~h}$ (MWCO $3500 \mathrm{Da}$ ). Finally, the residue was lyophilized to yield powdered materials.

\section{Acid-base titration}

Briefly, $5 \mathrm{mg}$ HA-Cds was dissolved in $2.5 \mathrm{~mL}$ deionized water and then added to $2.5 \mathrm{~mL}$ of $300 \mathrm{mM} \mathrm{NaCl}$ aqueous solution. $\mathrm{HCl}(1 \mathrm{~N})$ was added to adjust the $\mathrm{pH}$ to 2.0 . Aliquots of $0.1 \mathrm{~N}$ $\mathrm{NaOH}$ were added, and the solution $\mathrm{pH}$ was measured with a $\mathrm{pH}$ meter (pHS-25) after each addition. The buffering capacity, defined as the percentage of amine groups becoming deprotonated from $\mathrm{pH} 5.1$ to 7.4, was calculated using the following equation:

$$
\begin{aligned}
& \text { Buffering capacity }(\%)= 100\left[\left(\Delta V_{1 \mathrm{NaOH}}-\Delta V_{2 \mathrm{NaOH}}\right)\right. \\
&\times 0.1 \mathrm{M}] / N \mathrm{~mol}
\end{aligned}
$$

$\Delta V_{1 \mathrm{NaOH}}$ is the volume of $\mathrm{NaOH}$ solution $(0.1 \mathrm{M})$ required to raise the $\mathrm{pH}$ value of the HA-Cd solution from 5.1 to 7.4, $\Delta V_{2 \mathrm{NaOH}}$ is the volume of $\mathrm{NaOH}$ solution $(0.1 \mathrm{M})$ required to raise the $\mathrm{pH}$ value of the $\mathrm{NaCl}$ solution from 5.1 to 7.4, $N$ mol is the total moles of amine groups in the HA-Cds or PEI. For HACds, $N=5 \times 10^{-3} W_{N}$ content $/ 14$ ( $W_{N}$ content represents the $N$ content of the HA-Cds).

\section{Cytotoxicity assays and toxicity}

The toxicity of HA-Cd/DNA complexes was determined with a CellTiter 96®AQueous One Solution Cell Proliferation Assay. About 9000 cells per well were seeded into 96-well plates. After $24 \mathrm{~h}$, the HA-Cds were complexed with $0.2 \mu \mathrm{g}$ of DNA at various weight ratios for $30 \mathrm{~min}$. The cells were then incubated in 
a culture medium $(100 \mu \mathrm{L})$ containing the complexes for $24 \mathrm{~h}$. The solutions were then removed and $100 \mu \mathrm{L}$ PBS containing 20 $\mu \mathrm{L}$ CellTiter $96 \circledast A$ Aueous One Solution Cell Proliferation was added to each well for an additional $1 \mathrm{~h}$ incubation at $37^{\circ} \mathrm{C}$. Then, the absorbance of each sample was measured using an ELISA plate reader (model 680, BioRad) at a wavelength of $490 \mathrm{~nm}$. The cell survival was expressed as follows: cell viability $=\left(\mathrm{OD}_{\text {treated }} / \mathrm{OD}_{\text {control }}\right) \times 100 \%$. Besides, the cell viability of 25 kDa PEI was also determined.

\section{Transfection procedure}

The gene transfection of a series of complexes was investigated in HeLa cells and HEK293 cells. Cells were seeded in 24-well plates $\left(1.05 \times 10^{5}\right.$ cells per well) and grown to reach $70-80 \%$ cell confluence at $37^{\circ} \mathrm{C}$ for $24 \mathrm{~h}$ in $5 \% \mathrm{CO}_{2}$. Before transfection, the medium was replaced with a serum-free or a $10 \%$ serumcontaining culture medium containing HA-Cds/pDNA $(0.8 \mu \mathrm{g})$ complexes at various weight ratios. After $4 \mathrm{~h}$ under standard incubator conditions, the medium was replaced with fresh medium containing serum and incubated for another $20 \mathrm{~h}$.

For fluorescence microscopy assays, cells were transfected by complexes containing pEGFP-N1. After $24 \mathrm{~h}$ incubation, GFPexpressed cells were observed with an inverted fluorescence microscope (Nikon Eclipse TE 2000E) equipped with a cold Nikon camera.

For luciferase assays, cells were transfected by complexes containing pGL-3. For a typical assay in a 24 -well plate, $24 \mathrm{~h}$ post transfection as described above, cells were washed with cold PBS and lysed with $100 \mu \mathrm{L} 1 \times$ lysis reporter buffer (Promega). The luciferase activity was measured with a microplate reader (Model 550, BioRad, USA). The protein content of the lysed cell was determined by BCA protein assay. The TE was expressed as the relative fluorescence intensity per $\mathrm{mg}$ protein (RLU per $\mathrm{mg}$ protein). All the experiments were done in triplicate.

\section{Protein adsorption assay}

In brief, $1 \mathrm{~mL}$ of HA-Cd solution $\left(1 \mathrm{mg} \mathrm{mL}^{-1}\right)$ was mixed with 1 $\mathrm{mL}$ of bovine serum albumin solution $\left(2 \mathrm{mg} \mathrm{mL}^{-1}\right)$. After shaking for $0.5 \mathrm{~h}$ at $37{ }^{\circ} \mathrm{C}$ and centrifuging at full-speed, the supernatant was carefully collected. The concentration of BSA in the supernatant was determined by BCA protein assay. The protein adsorbed on the polyplexes was calculated using the following equation:

$$
q=\left(C_{\mathrm{i}}-C_{\mathrm{s}}\right) \times V / m
$$

where $C_{\mathrm{i}}$ and $C_{\mathrm{s}}$ are the initial BSA concentration $\left(2 \mathrm{mg} \mathrm{mL}^{-1}\right)$ and the BSA concentration in the supernatant after adsorption experiments, respectively; $V=2 \mathrm{~mL}$ and $m=1 \mathrm{mg}$.

\section{Inhibition studies}

To probe the internalization mechanism of the HA-Cd/DNA complexes, the cellular uptake study was performed at $4{ }^{\circ} \mathrm{C}$ or in the presence of various endocytic inhibitors with a serumfree or a $10 \%$ serum-containing medium. Briefly, cells were incubated with complexes at $4{ }^{\circ} \mathrm{C}$ for $4 \mathrm{~h}$, wherein the energy- dependent endocytosis was blocked. Otherwise, cells were preincubated with various endocytic inhibitors including cytochalasin $\mathrm{D}\left(10 \mathrm{mg} \mathrm{mL}^{-1}\right)$, wortmannin $(50 \mathrm{nM})$, genistein $(200 \mu \mathrm{M})$, nocodazole $(33 \mu \mathrm{M})$, and chlorpromazine $\left(10 \mu \mathrm{g} \mathrm{mL}^{-1}\right)$. Following pretreatment for $30 \mathrm{~min}$, the inhibitor solutions were replaced by the freshly prepared test complexes (Cy5-labeled plasmid DNA) in media containing inhibitors at the same concentrations. After further incubation for $4 \mathrm{~h}$, cells were harvested and analyzed by flow cytometry. In the study, the groups in the presence of test complexes at $37^{\circ} \mathrm{C}$ but without inhibitor treatment were used as controls. The results were represented as percentage uptake levels of control cells.

\section{Cellular uptake of plasmid DNA (flow cytometry)}

The cellular uptake of the HA-Cd/Cy5-labeled DNA complexes was analyzed by flow cytometry. A Label IT Cy5 Labeling Kit was used to label pDNA according to the manufacturer's protocol. Briefly, HeLa cells were seeded in 12-well plates $\left(2.0 \times 10^{5}\right.$ cells per well) and allowed to attach and grow for $24 \mathrm{~h}$. The medium was exchanged with serum-free or serum-containing medium. Cells were incubated with complexes containing Cy5-labeled DNA $(2 \mu \mathrm{g}$ of DNA per well, optimal weight ratio of each sample) in media for $4 \mathrm{~h}$ at $37^{\circ} \mathrm{C}$. Subsequently, the cells were washed with $1 \times$ PBS and harvested with $0.25 \%$ trypsin/EDTA and resuspended in $1 \times$ PBS. The mean fluorescence intensity was analyzed using a flow cytometer (Becton Dickinson and Company). The Cy5-labeled plasmid DNA uptake was measured in the FL4 channel using the red diode laser (633 nm).

\section{Confocal laser scanning microscopy (CLSM) analysis}

HeLa cells or HepG2 cells were seeded in a $35 \mathrm{~mm}$ confocal dish $(\Phi=15 \mathrm{~mm})$ at a density of $2 \times 104$ cells per well. After $24 \mathrm{~h}$ under standard incubation conditions, the medium was exchanged with serum-containing medium. For the internalization assay, cells were incubated with HA-Cds or PEI/Cy5labeled pGL-3 (1.6 $\mu \mathrm{g}$ of DNA per well, $\mathrm{w} / \mathrm{w}=10)$ complexes in media for $1 \mathrm{~h}$ and $4 \mathrm{~h}$ at $37^{\circ} \mathrm{C}$. For the cellular trafficking assay, cells were incubated with HA-Cd/Cy5-labeled pGL-3 (1.6 $\mu \mathrm{g}$ of DNA per well, $\mathrm{w} / \mathrm{w}=10)$ complexes in media for $1 \mathrm{~h}, 4 \mathrm{~h}$, and $24 \mathrm{~h}$ at $37^{\circ} \mathrm{C}$. For the HA competition assay, cells were firstly incubated with HA $(1 \mathrm{mg})$ for $2 \mathrm{~h}$ then further incubated with HA-Cds for another $4 \mathrm{~h}$. Finally, cells were rinsed twice with PBS (pH 7.4) and fixed with $4 \%$ paraformaldehyde for $10 \mathrm{~min}$. The CLSM observation was performed using a Leica TCS SP5 instrument at excitation wavelengths of $405 \mathrm{~nm}$ and $488 \mathrm{~nm}$ for HA-Cds and $633 \mathrm{~nm}$ for Cy5 (red).

\section{Acknowledgements}

This work was financially supported by the National Natural Science Foundation of China (Nos. 21672155, 21472131, 21232005). We also thank the Analytical \& Testing Center of Sichuan University for the TEM analysis. 


\section{References}

1 M. Morille, C. Passirani, A. Vonarbourg, A. Clavreul and J.-P. Benoit, Biomaterials, 2008, 29, 3477-3496.

2 H. Jin, A. Kanthasamy, A. Ghosh, V. Anantharam, B. Kalyanaraman and A. G. Kanthasamy, Biochim. Biophys. Acta, Mol. Basis Dis., 2014, 1842, 1282-1294.

3 O. Sankoh, S. Arthur, B. Nyide and M. Weston, HIV AIDS Rev., 2015, 14, 1-8.

4 H. Zhang, H. Wu, J. Wang, Y. Yang, D. Wu, Y. Zhang, Y. Zhang, Z. Zhou and S. Yang, Biomaterials, 2015, 42, 66-77.

5 R. Srinivas, S. Samanta and A. Chaudhuri, Chem. Soc. Rev., 2009, 38, 3326-3338.

6 C. H. Jones, C.-K. Chen, A. Ravikrishnan, S. Rane and B. A. Pfeifer, Mol. Pharm., 2013, 10, 4082-4098.

7 L. Li, S. Puhl, L. Meinel and O. Germershaus, Biomaterials, 2014, 35, 7929-7939.

8 S. Y. Lim, W. Shen and Z. Gao, Chem. Soc. Rev., 2015, 44, 362381.

9 Q. Xu, T. Kuang, Y. Liu, L. Cai, X. Peng, T. S. Sreeprasad, P. Zhao, Z. Yu and N. Li, J. Mater. Chem. B, 2016, 4, 72047219.

10 H. Ding, F. Du, P. Liu, Z. Chen and J. Shen, ACS Appl. Mater. Interfaces, 2015, 7, 6889-6897.

11 Y. Liu, Y. Liu, S.-J. Park, Y. Zhang, T. Kim, S. Chae, M. Park and H.-Y. Kim, J. Mater. Chem. A, 2015, 3, 17747-17754.

12 H. He, X. Wang, Z. Feng, T. Cheng, X. Sun, Y. Sun, Y. Xia, S. Wang, J. Wang and X. Zhang, J. Mater. Chem. B, 2015, 3, 4786-4789.

13 Y. Guo, Z. Wang, H. Shao and X. Jiang, Carbon, 2013, 52, 583-589.

14 H. Wu, C. Mi, H. Huang, B. Han, J. Li and S. Xu, J. Lumin., 2012, 132, 1603-1607.

15 Z.-C. Yang, M. Wang, A. M. Yong, S. Y. Wong, X.-H. Zhang, H. Tan, A. Y. Chang, X. Li and J. Wang, Chem. Commun., 2011, 47, 11615-11617.

16 Y. Hu, J. Yang, L. Jia and J.-S. Yu, Carbon, 2015, 93, 999-1007.

17 C. Liu, P. Zhang, X. Zhai, F. Tian, W. Li, J. Yang, Y. Liu, H. Wang, W. Wang and W. Liu, Biomaterials, 2012, 33, 3604-3613.

18 L. Wang, X. Wang, A. Bhirde, J. Cao, Y. Zeng, X. Huang, Y. Sun, G. Liu and X. Chen, Adv. Healthcare Mater., 2014, 3, 1203-1209.

19 P. Pierrat, R. Wang, D. Kereselidze, M. Lux, P. Didier, A. Kichler, F. Pons and L. Lebeau, Biomaterials, 2015, 51, 290-302.

20 X. Zhai, W. Wang, C. Wang, Q. Wang and W. Liu, J. Mater. Chem., 2012, 22, 23576-23586.

21 J. Sun, F. Zeng, H. Jian and S. Wu, Polym. Chem., 2013, 4, 5810-5818.

22 K.-M. Xiu, N.-N. Zhao, W.-T. Yang and F.-J. Xu, Acta Biomater., 2013, 9, 7439-7448.

23 W. Wang, X. Ji, A. Kapur, C. Zhang and H. Mattoussi, J. Am. Chem. Soc., 2015, 137, 14158-14172.

24 H. Tian, Z. Guo, L. Lin, Z. Jiao, J. Chen, S. Gao, X. Zhu and X. Chen, J. Controlled Release, 2014, 174, 117-125.
25 L. Jin, X. Zeng, M. Liu, Y. Deng and N. He, Theranostics, 2014, 4, 240-255.

26 J. G. Piao, S. G. Ding, L. Yang, C. Y. Hong and Y. Z. You, Biomacromolecules, 2014, 15, 2907-2913.

27 M. H. Ramadan, J. E. Prata, O. Karacsony, G. Duner and N. R. Washburn, Langmuir, 2014, 30, 7485-7495.

28 H. Y. Yoon, H. R. Kim, G. Saravanakumar, R. Heo, S. Y. Chae, W. Um, K. Kim, I. C. Kwon, J. Y. Lee, D. S. Lee, J. C. Park and J. H. Park, J. Controlled Release, 2013, 172, 653-661.

29 Y. He, G. Cheng, L. Xie, Y. Nie, B. He and Z. Gu, Biomaterials, 2013, 34, 1235-1245.

30 H. Tian, L. Lin, J. Chen, X. Chen, T. G. Park and A. Maruyama, J. Controlled Release, 2011, 155, 47-53.

31 J. H. Park, H. J. Cho, H. Y. Yoon, I. S. Yoon, S. H. Ko, J. S. Shim, J. H. Cho, J. H. Park, K. Kim, I. C. Kwon and D. D. Kim, J. Controlled Release, 2014, 174, 98-108.

32 V. N. Mehta, S. Jha, H. Basu, R. K. Singhal and S. K. Kailasa, Sens. Actuators, B, 2015, 213, 434-443.

33 A. Dehshahri, R. K. Oskuee, W. T. Shier, A. Hatefi and M. Ramezani, Biomaterials, 2009, 30, 4187-4194.

34 S. Zhang, H. Gao and G. Bao, ACS Nano, 2015, 9, 8655-8671. 35 Y. Liu and T. M. Reineke, J. Am. Chem. Soc., 2005, 127, 30043015.

36 Y. Zhou, B. Yang, X. Ren, Z. Liu, Z. Deng, L. Chen, Y. Deng, L.-M. Zhang and L. Yang, Biomaterials, 2012, 33, 4731-4740.

37 Q.-F. Zhang, Q.-Y. Yu, Y. Geng, J. Zhang, W.-X. Wu, G. Wang, Z. Gu and X.-Q. Yu, ACS Appl. Mater. Interfaces, 2014, 6, 15733-15742.

38 H. Gao, W. Shi and L. B. Freund, Proc. Natl. Acad. Sci. U. S. A., 2005, 102, 9469-9474.

39 C. He, Y. Hu, L. Yin, C. Tang and C. Yin, Biomaterials, 2010, 31, 3657-3666.

40 Q. Guo, Y.-H. Liu, M.-M. Xun, J. Zhang, Z. Huang, X.-D. Zhou and X.-Q. Yu, J. Mater. Chem. B, 2015, 3, 2660-2670.

41 W.-J. Yi, Q.-F. Zhang, J. Zhang, Q. Liu, L. Ren, Q.-M. Chen, L. Guo and X.-Q. Yu, Acta Biomater., 2014, 10, 1412-1422.

42 Q.-F. Zhang, W.-J. Yi, B. Wang, J. Zhang, L. Ren, Q.-M. Chen, L. Guo and X.-Q. Yu, Biomaterials, 2013, 34, 5391-5401.

43 J. Ge, Q. Jia, W. Liu, L. Guo, Q. Liu, M. Lan, H. Zhang, X. Meng and P. Wang, Adv. Mater., 2015, 27, 4169-4177.

44 J. Zhang, Z. Wang, W. Lin and S. Chen, Biomaterials, 2014, 35, 7909-7918.

45 B. Wang, C. He, C. Tang and C. Yin, Biomaterials, 2011, 32, 4630-4638.

46 S. D. Conner and S. L. Schmid, Nature, 2003, 422, 37-44.

47 S.-F. Peng, M. T. Tseng, Y.-C. Ho, M.-C. Wei, Z.-X. Liao and H.-W. Sung, Biomaterials, 2011, 32, 239-248.

48 N. Araki, M. T. Johnson and J. A. Swanson, J. Cell Biol., 1996, 135, 1249-1260.

49 O. P. Perumal, R. Inapagolla, S. Kannan and R. M. Kannan, Biomaterials, 2008, 29, 3469-3476.

50 K. L. Douglas, Biotechnol. Prog., 2008, 24, 871-883.

51 C. Y. M. Hsu and H. Uludağ, Biomaterials, 2012, 33, 78347848.

52 H. Wu, H. Shi, Y. Wang, X. Jia, C. Tang, J. Zhang and S. Yang, Carbon, 2014, 69, 379-389. 
53 E. Song, W. Han, C. Li, D. Cheng, L. Li, L. Liu, G. Zhu, Y. Song and W. Tan, ACS Appl. Mater. Interfaces, 2014, 6, 1188211890.

54 J. Kim, J. Park, H. Kim, K. Singha and W. J. Kim, Biomaterials, 2013, 34, 7168-7180.
55 A. Barnard, P. Posocco, S. Pricl, M. Calderon, R. Haag, M. E. Hwang, V. W. Shum, D. W. Pack and D. K. Smith, J. Am. Chem. Soc., 2011, 133, 20288-20300.

56 Y. Huang, X. Yang, T. Xu, Q. Kong, Y. Zhang, Y. Shen, Y. Wei, G. Wang and K. J. Chang, Int. J. Oncol., 2016, 49, 153-163. 